\title{
ESTIMATING THE SHEAR MODULUS OF SOILS BASED ON SURFACE ROUGHNESS
}

\author{
S. Karthiga Nambi ${ }^{1}$, R. Saravanya ${ }^{2}$, M.Murugan ${ }^{3}$ \\ ${ }^{1}$ Undergraduate Student, Civil Department, V V College Of Engineering, Tamil Nadu, India \\ ${ }^{2}$ Undergraduate Student, Civil Department, $V$ V College Of Engineering, Tamil Nadu, India \\ ${ }^{3}$ Assistant Professor, Civil Department, VV College of Engineering, Tamil Nadu, India
}

\begin{abstract}
The purpose of this paper is to estimate the initial shear modulus of soils based on the surface roughness of materials. Interface shear modulus depends on soil type \& gradation and surface roughness of specimens. By considering all the factors, a simple mathematical equation was given by Murugan et al. (2014) for the interface shear modulus between soil and structural material. Interface shear modulus of soil was evaluated by using the mathematical equation given by Murugan et al. (2014).Result indicates that interface shear modulus increases with the increment of the surface roughness of the specimens used in this study. The highest peak shear modulus is achieved when the surface is rough. This study is very important in the field of earthquake geotechnical engineering.
\end{abstract}

Keywords: Soil, Interface shear modulus, Initial shear modulus, surface roughness.

\section{INTRODUCTION}

Shear modulus is a most important property for evaluating the dynamic responses of soil structures at different sites. Seismic waves altered as they pass through soil layers, from bedrock to surface, change frequencies and amplitudes and these modifications result in different ground motion characteristics. Therefore, the effects of earthquakes in buildings and earthworks depend on the shear moduli of soil strata underlying the affected sites. In recent years many studies were performed to develop a general model to estimate shear modulus at small strain level. The initial shear modulus $\left(\mathrm{G}_{0}\right)$ is a very important parameter for seismic ground response analysis and also for a variety of geotechnical applications. A considerable number of empirical relationships have been proposed for estimating initial shear modulus for different kind of soils: [(Hardin and Black, 1969), (Iwasaki and Taksuoka, 1977), (Biarez et al., 1999)]. Existing models for unsaturated soils are limited on empirical models for initial shear modulus [Mancuso et al., 2002], [Biglari et al., 2010b] because the most of the literature experiments are included in investigating small strain behavior. This paper presents the results of initial shear modulus of soils (sand, gravel and SC soil) based on the empirical model proposed by Murugan et al., 2014.

\section{SOIL CHARACTERISTICS}

Three different soils were selected. The index and engineering properties of these soils are presented in Table 1 to 3 . The soils were classified according to IS: 1498 - 1970.
Table 1.Engineering properties of the sandy soils used in the

\begin{tabular}{|l|l|l|}
\hline Soil Property & $\begin{array}{l}\text { Well graded } \\
\text { sand }\end{array}$ & $\begin{array}{l}\text { Poorly } \\
\text { graded sand }\end{array}$ \\
\hline Grain size analysis: & $0.36 \mathrm{~mm}$ & $0.29 \mathrm{~mm}$ \\
Effective size, $\mathrm{D}_{10}$ & 6.46 & 2.14 \\
Coefficient of uniformity, & 2.08 & 0.94 \\
$\mathrm{C}_{\mathrm{u}}$ & $\mathrm{SW}$ & $\mathrm{SP}$ \\
Coefficient of curvature, $\mathrm{C}_{\mathrm{c}}$ & $\mathrm{SW}$ & \\
Classification (unified) & & 2.62 \\
\hline Specific gravity, $\mathrm{G}_{\mathrm{s}}$ & 2.65 & \\
\hline Dry unit weight: & & $16.81 \mathrm{kN} / \mathrm{m}^{3}$ \\
Maximum, $\gamma_{\mathrm{d}}(\max )$ & $17.12 \mathrm{kN} / \mathrm{m}^{3}$ & $16.25 \mathrm{kN} / \mathrm{m}^{3}$ \\
Minimum, $\gamma_{\mathrm{d}}(\min )$ & $15.72 \mathrm{kN} / \mathrm{m}^{3}$ & 15.25
\end{tabular}

Table 2.Engineering properties of the gravel soils used in the study

\begin{tabular}{|l|l|l|}
\hline Soil Property & $\begin{array}{l}\text { Well graded } \\
\text { gravel }\end{array}$ & $\begin{array}{l}\text { Poorly } \\
\text { graded } \\
\text { gravel }\end{array}$ \\
\hline Grain size analysis: & & \\
Effective size, $\mathrm{D}_{10}$ & $\begin{array}{l}2.52 \mathrm{~mm} \\
4.42\end{array}$ & $\begin{array}{l}2.31 \mathrm{~mm} \\
3.62\end{array}$ \\
Coefficient of uniformity, & $\begin{array}{l}\text { (1.24 } \\
\mathrm{C}_{\mathrm{u}}\end{array}$ & $\mathrm{GP}$ \\
Coefficient of curvature, $\mathrm{C}_{\mathrm{c}}$ & $\mathrm{GW}$ & \\
Classification (unified) & & 2.65 \\
\hline Specific gravity, $\mathrm{G}_{\mathrm{s}}$ & 2.68 & \\
\hline $\begin{array}{l}\text { Dry unit weight: } \\
\text { Maximum, } \gamma_{\mathrm{d}}(\max )\end{array}$ & $18.86 \mathrm{kN} / \mathrm{m}^{3}$ & $18.12 \mathrm{kN} / \mathrm{m}^{3}$ \\
Minimum, $\gamma_{\mathrm{d}}(\min )$ & $16.68 \mathrm{kN} / \mathrm{m}^{3}$ & $16.25 \mathrm{kN} / \mathrm{m}^{3}$ \\
\hline
\end{tabular}


Table 3.Engineering properties of the SC soil used in the study

\begin{tabular}{|l|l|l|l|l|l|l|l|l|}
\hline \multicolumn{4}{|l|}{ \% Passing } & \multicolumn{4}{|l|}{ Atterberg Limit } & \multicolumn{2}{l|}{ Dry unit weight $\left(\mathrm{kN} / \mathrm{m}^{3}\right)$} & $\begin{array}{l}\text { Type of soil } \\
\text { (IS 1498) }\end{array}$ \\
\hline $4.75 \mathrm{~mm}$ & $425 \mu$ & $75 \mu$ & LL $(\%)$ & PL $(\%)$ & Ip & $\gamma_{\mathrm{d}}(\max )$ & $\gamma_{\mathrm{d}}(\min )$ & SC \\
\hline 99 & 64 & 49 & 47 & 26 & 21 & 15.25 & 13.12 & \\
\hline
\end{tabular}

\section{SURFACE ROUGHNESS OF SPECIMENS}

Three different types of specimens were used for this study; concrete, steel and timber with varying surface roughness. The specimens are shown in Fig. 1 to 3. Surface roughness of the material is one of the important factors that influence the shear strength parameters. Generally, Absolute roughness $\left(\mathrm{R}_{\mathrm{a}}\right)$ is considered for calculating interface friction between two different materials. It is a measure of the surface roughness of a material. This roughness is generally expressed in units of length as the absolute roughness of the material. Surface roughness of specimens used in the study is given in the Table 4 .

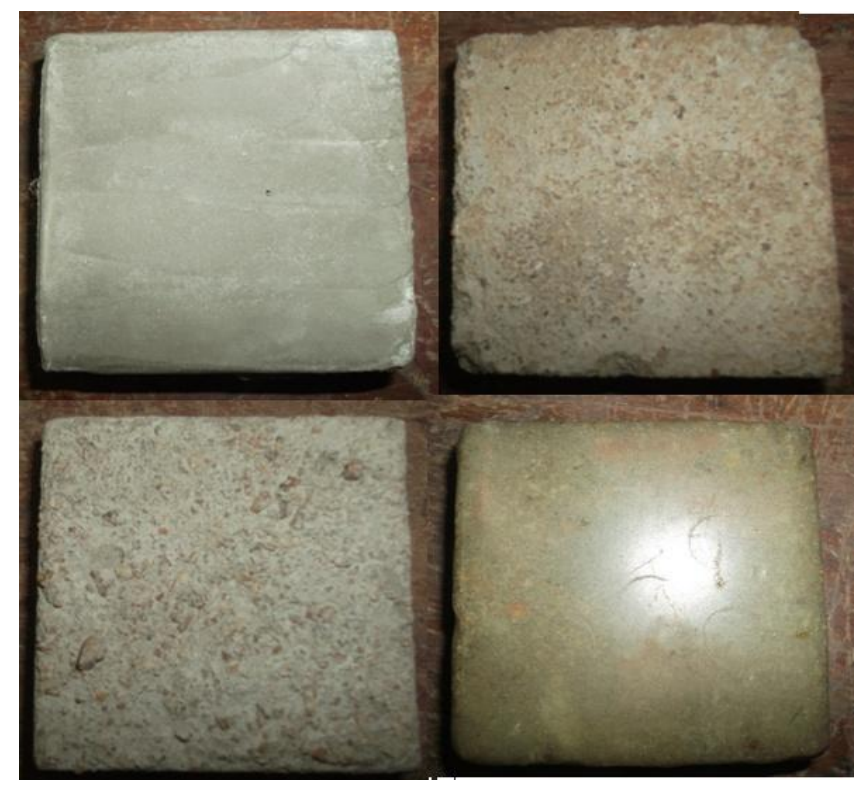

Fig. 1.Concrete specimens used in this study

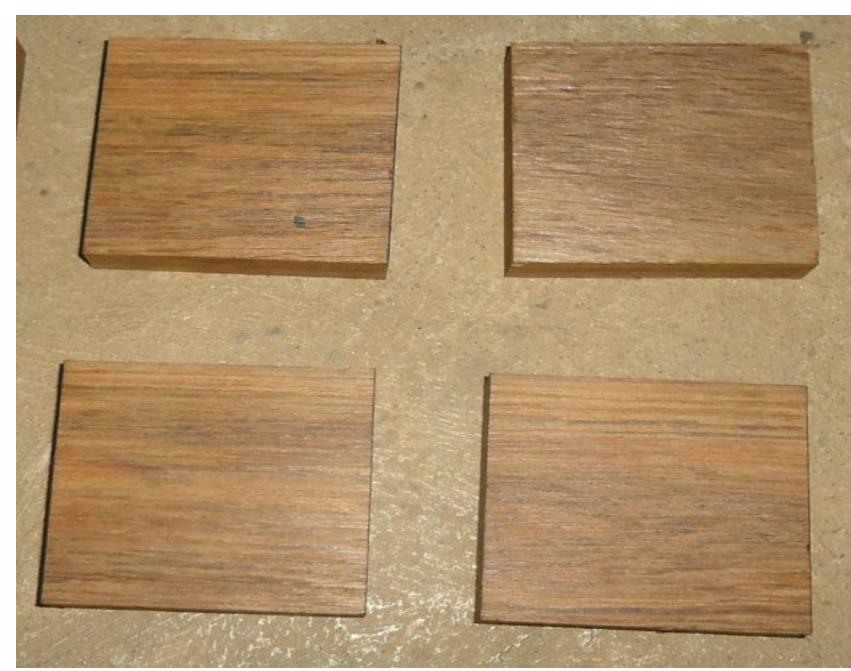

Fig. 2.Timber specimens used in this study

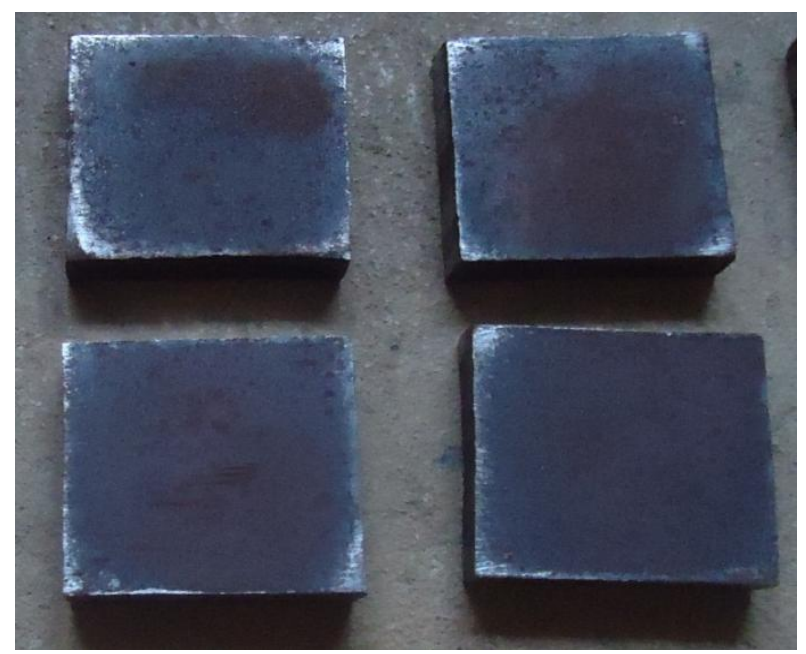

Fig. 3.Steel specimens used in this study

Table 4 Surface roughness of specimens

\begin{tabular}{|l|l|}
\hline Steel specimens & $\begin{array}{l}\text { Surface } \\
\text { roughness, } \mathrm{R}_{\mathrm{a}} \\
(\mu \mathrm{m})\end{array}$ \\
\hline Smooth surface concrete & 0.62 \\
\hline Medium surface concrete & 0.88 \\
\hline Rough surface concrete & 1.82 \\
\hline Epoxy coated concrete & 0.44 \\
\hline Smooth surface timber & 0.48 \\
\hline Medium surface timber & 0.70 \\
\hline Rough surface timber & 0.86 \\
\hline Epoxy coated timber & 0.44 \\
\hline Smooth surface steel & 0.51 \\
\hline Medium surface steel & 0.76 \\
\hline Rough surface steel & 0.92 \\
\hline Epoxy coated steel & 0.44 \\
\hline
\end{tabular}

\section{AN EMPIRICAL MODEL FOR PREDICTING}

\section{THE INTERFACE SHEAR MODULUS}

Interface shear modulus depends on soil type \& gradation and surface roughness of specimens. By considering all the factors, a simple mathematical equation was given by Murugan et al. (2014) for the interface shear modulus between soil and structural material.

Shear modulus between soil and structural material,

$$
\mathrm{G}=\mathrm{a}+\mathrm{b}\left(\mathrm{R}_{\mathrm{a}}\right) \quad \mathrm{N} / \mathrm{mm}^{2}
$$

where,

$\mathrm{R}_{\mathrm{a}}=$ Surface roughness of structural material $(\mu \mathrm{m})$ $\mathrm{a} \& \mathrm{~b}$ are constants depends on soil type \& gradation. The values of a $\&$ bare tabulated in Table 5 . 
Table 5 Constants a \& b (Murugan et al. (2014)

\begin{tabular}{|l|l|l|}
\hline \multirow{2}{*}{ Type of soil } & Constants \\
\cline { 2 - 3 } & $\mathrm{a}$ & $\mathrm{b}$ \\
\hline Well graded sand & 55.32 & 11.76 \\
\hline Poorly graded sand & 51.19 & 11.67 \\
\hline Well graded gravel & 62.24 & 11.45 \\
\hline Poorly graded gravel & 58.55 & 11.51 \\
\hline Sandy clay & 40.34 & 15.72 \\
\hline
\end{tabular}

\section{TEST RESULTS AND DISCUSSIONS}

Interface shear modulus against surface roughness of concrete, steel and timber specimens with sand, gravel and $\mathrm{SC}$ soil isgiven in Table 6 to 8 . It indicates that interface shear modulus increases with the increment of the surface roughness of the specimens used in this study. The highest peak shear modulus is achieved when the surface is rough. This study is very important in the field of earthquake geotechnical engineering to evaluate the performance of soil under dynamic loads.

Table 6. Shear modulus of soil against concrete surfaces

\begin{tabular}{|l|l|l|l|l|l|l|}
\hline \multirow{2}{*}{ Type of Soil } & \multicolumn{2}{|l|}{ Constant } & \multicolumn{2}{l|}{ Shear Modulus, N/mm ${ }^{2}$} \\
\cline { 2 - 7 } & $\mathrm{a}$ & $\mathrm{b}$ & Smooth & Medium & Rough & Epoxy coated \\
\hline Well graded sand & 55.32 & 11.76 & 62.61 & 65.67 & 76.72 & 60.49 \\
Poorly graded sand & 51.19 & 11.67 & 58.43 & 61.46 & 72.43 & 56.32 \\
Well graded gravel & 62.24 & 11.45 & 69.34 & 72.32 & 83.08 & 67.28 \\
Poorly graded gravel & 58.55 & 11.51 & 65.69 & 68.68 & 79.50 & 63.61 \\
Clayey sand & 40.34 & 15.72 & 50.09 & 54.17 & 68.95 & 47.26 \\
\hline
\end{tabular}

Table 7.Shear modulus of soil against steel surfaces

\begin{tabular}{|c|c|c|c|c|c|c|}
\hline \multirow[t]{2}{*}{ Type of Soil } & \multicolumn{2}{|c|}{ Constant } & \multicolumn{4}{|c|}{ Shear Modulus, N/mm ${ }^{2}$} \\
\hline & $\mathrm{a}$ & $\mathrm{b}$ & Smooth & Medium & Rough & Epoxy coated \\
\hline Well graded sand & 55.32 & 11.76 & 61.32 & 64.26 & 66.14 & 60.49 \\
\hline Poorly graded sand & 51.19 & 11.67 & 57.14 & 60.06 & 61.93 & 56.32 \\
\hline Well graded gravel & 62.24 & 11.45 & 68.08 & 70.94 & 72.77 & 67.28 \\
\hline Poorly graded gravel & 58.55 & 11.51 & 64.42 & 67.30 & 69.14 & 63.61 \\
\hline Clayey sand & 40.34 & 15.72 & 48.36 & 52.29 & 54.80 & 47.26 \\
\hline
\end{tabular}

Table 8. Shear modulus of soil against timber surfaces

\begin{tabular}{|l|l|l|l|l|l|l|}
\hline \multirow{2}{*}{ Type of Soil } & \multicolumn{2}{l}{ Constant } & \multicolumn{2}{l|}{ Shear Modulus, N/mm ${ }^{2}$} \\
\cline { 2 - 7 } & $\mathrm{a}$ & $\mathrm{b}$ & Smooth & Medium & Rough & Epoxy coated \\
\hline Well graded sand & 55.32 & 11.76 & 60.96 & 63.55 & 65.43 & 60.49 \\
Poorly graded sand & 51.19 & 11.67 & 56.79 & 59.36 & 61.23 & 56.32 \\
Well graded gravel & 62.24 & 11.45 & 67.74 & 70.26 & 72.09 & 67.28 \\
Poorly graded gravel & 58.55 & 11.51 & 64.07 & 66.61 & 68.45 & 63.61 \\
Clayey sand & 40.34 & 15.72 & 47.89 & 51.34 & 53.86 & 47.26 \\
\hline
\end{tabular}

\section{CONCLUSIONS}

Examining the data, it could be seen that, the shear modulus at the interface increases with increase in surface roughness of specimens. The highest peak shear modulus is achieved when the surface is rough. Interface shear modulus also based on the type of soil and soil gradation. This study is very important in the field of earthquake geotechnical engineering to evaluate the performance of soil under dynamic loads.

\section{REFERENCES}

[1]. Hardin, B.O. and Black, W.L. (1969), "Closure to vibration modulus of normally consolidated clays". Journal of Soil Mechanics and Foundations Division, ASCE, vol. 95, no. SM6, pp. 1531-1537.

[2]. Iwasaki, T. and Taksuoka, F. (1977), "Effects of Grain size and grading on dynamic shear moduli of sands". Soils and Foundations, vol. 17, no. 3, pp. 19-35.
[3]. Biarez, J.; Gomes Correia, A.; Liu, H. and Taibi, S. (1999), "Stress-strain characteristics of soils interesting the serviceability of geotechnical structures". 2nd International Symposium on Pre-failure Deformation Characteristics of Geomaterials, Torino (in press).

[4]. Mancuso, C., Vassallo, R., and d'Onofrio, A. (2002), "Small strain behavior of a silty sand in controlled-suction resonant column - torsional shear tests". Canadian Geotechnical Journal, Vol. 39, 22-31.

[5]. Biglari, M., Mancuso, C., d'Onofrio, A., Jafari, M.K., and Shafiee. (2010b), "A. Modelling the initial shear stiffness of unsaturated soils as a function of the coupled effects of the void ratio and the degree of saturation". Computers and Geotechnics, DOI:10.1016/j.compgeo. 2011.04.007.

[6]. Murugan, M., Natarajan, C. and Muthukkumaran, K. "Performance of FRP strengthened RC piles subjected to static and cyclic lateral loads", PhD thesis, National Institute of Technology, Tiruchirappalli, 2014. 